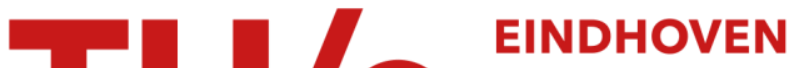 \\ UNIVERSITY OF \\ TECHNOLOGY
}

\section{Ultradrawing of high molecular weight polyethylene}

Citation for published version (APA):

Lemstra, P. J., \& Smith, P. (1980). Ultradrawing of high molecular weight polyethylene. British Polymer Journal, 12(4), 212-214. https://doi.org/10.1002/pi.4980120415

DOI:

10.1002/pi.4980120415

Document status and date:

Published: 01/01/1980

\section{Document Version:}

Publisher's PDF, also known as Version of Record (includes final page, issue and volume numbers)

\section{Please check the document version of this publication:}

- A submitted manuscript is the version of the article upon submission and before peer-review. There can be important differences between the submitted version and the official published version of record. People interested in the research are advised to contact the author for the final version of the publication, or visit the $\mathrm{DOI}$ to the publisher's website.

- The final author version and the galley proof are versions of the publication after peer review.

- The final published version features the final layout of the paper including the volume, issue and page numbers.

Link to publication

\section{General rights}

Copyright and moral rights for the publications made accessible in the public portal are retained by the authors and/or other copyright owners and it is a condition of accessing publications that users recognise and abide by the legal requirements associated with these rights.

- Users may download and print one copy of any publication from the public portal for the purpose of private study or research.

- You may not further distribute the material or use it for any profit-making activity or commercial gain

- You may freely distribute the URL identifying the publication in the public portal.

If the publication is distributed under the terms of Article 25fa of the Dutch Copyright Act, indicated by the "Taverne" license above, please follow below link for the End User Agreement:

www.tue.nl/taverne

Take down policy

If you believe that this document breaches copyright please contact us at:

openaccess@tue.nl

providing details and we will investigate your claim. 


\title{
Ultra-drawing of High Molecular Weight Polyethylene
}

Piet J. Lemstra and Paul Smith

\begin{abstract}
The effective drawability of solution-cast or -spun high molecular weight polyethylene is enhanced significantly in comparison with an identical polymer sample that is crystallised from the melt.

The maximum attainable draw ratio, which primarily determines the final mechanical properties, increases continuously with decreasing initial polymer concentration in solution. $\mathrm{A}$ tensile strength of $3.2 \mathrm{GPa}$ and an axial Young's modulus of $120 \mathrm{GPa}$ could be obtained by drawing high molecular weight polyethylene cast from a $1 \%$ polymer solution. This phenomenon of increased drawability is discussed in terms of a reduced number of entanglements per macromolecule in solution-cast polyethylene.
\end{abstract}

\section{INTRODUCTION}

In the past decade considerable effort has been devoted towards the production of high-strength/high-modulus polymeric fibres. ${ }^{1}$ An outstanding achievement in this field has been the development of aromatic polyamide fibres (Kevlar) by Du Pont scientists, having tensile strength up to $3 \mathrm{GPa}$ and axial Young's modulus of about $150 \mathrm{GPa}^{2}$ In this particular case polymer chemists designed rigid chain molecules which are prone to orient during flow. Basically this concept applies equally well to the new class of aromatic polyesters, which have the merit over aromatic polyamides of being processable as thermoplastic materials. ${ }^{3}$

The simple linear polyethylene molecule is, however, also an excellent candidate for high-strength/high-modulus fibres due to its small chain cross-sectional area and the zig-zag chain conformation in the crystalline state. Theoretical estimated values of an axial Young's modulus of about $250 \mathrm{GPa}^{4}$ and tensile strength up to $19 \mathrm{GPa}^{5}$ have been reported in the literature. Yet, these high values have not been attained experimentally. Substantial progress has recently been made to bridge the gap between the rather poor mechanical performance of isotropic polyethylene and the aforementioned ultimate values ${ }^{1}$ by extension and alignment of the flexible polyethylene molecules into a parallel register. Deformation of the solid state has been shown to be most effective to reach a high degree of chain orientation. This can be achieved by solid-state extrusion ${ }^{6}$ or drawing polyethylene below its end-melting temperature. ${ }^{7}$ It is now well established that the axial modulus rapidly increases with deformation ratio, and moduli up to 70 $\mathrm{GPa}$ which equals about $1 / 4$ of the theoretical value, have been reported. 1 Oriented polyethylene structures obtained by solid-state extrusion or drawing of melt-spun fibres in general show lack of strength, which is typically below $1 \mathrm{GPa}$. High molecular weight is prerequisite for high tensile strength. ${ }^{8,9}$ Unfortunately at increasing molecular weight the polymer material increasingly resists deformation due to a greater number of entanglements per molecule and upon drawing fracture already occurs before a high degree of chain orientation is obtained. An interesting phenomenon is that by selected crystallisation conditions the drawability of polyethylene having a molecular weight significantly. ${ }^{10}$ These procedures are only effective for

Central Laboratory, DSM, Geleen, The Netherlands.

(Manuscript received 29 October 1980) the lower molecular weight range and but slightly affect the drawbility of polyethylene having a molecular weight exceeding $5 \times 10^{5} \mathrm{~kg} / \mathrm{kmol}$. Recently, we reported a drastically improved drawability of ultra-high molecular weight polyethylene $\left(\overline{\mathrm{M}}_{\mathrm{w}}=1.5 \times 10^{6} \mathrm{~kg} / \mathrm{kmol}\right)$ by reduction of the number of entanglements per molecule through solution-spinning or casting from semi-dilute solution. ${ }^{11,12}$ For example, this very high molecular weight polyethylene sample, spun from a $2 \% \mathrm{w} / \mathrm{w}$ solution in decalin, could be drawn at $120^{\circ} \mathrm{C}$ to $30 \mathrm{x}$ its original length resulting in a fibrous structure with a tensile strength of $3 \mathrm{GPa}$ and a Young's modulus of $100 \mathrm{GPa}$. An identical polymer sample, crystallised from the melt, could be drawn only $6 \times$ at $120^{\circ} \mathrm{C}$ with correspondingly poor mechanical properties of the oriented material. In a previous study 13 we reported on the difference between the drawability of high molecular weight polyethylene spun from dilute, or concentrated solutions respectively. In the latter case no significant improvement of the maximum attainable draw ratio with respect to melt-crystallised polymer was found. In this paper the influence of initial polymer concentration on the drawability of solution-spun or cast high molecular weight polyethylene is reported and discussed qualitatively in terms of the number of entanglements per molecule. Moreover, we have tried to extend the discussion towards the drawing behaviour of polyethylene in general.

\section{EXPERIMENTAL}

High molecular weight polyethylene, Hostalen Gur $\left(\overline{\mathrm{M}}_{\mathrm{w}}=\right.$ $1.5 \times 10^{6}$ and $\bar{M}_{n}=2 \times 10^{5} \mathrm{~kg} / \mathrm{kmol}$ ) was used in this study. Decalin (J. T. Baker Chemicals) was used as solvent and di- $t$-butyl-p-cresol (DBPC) was added as stabiliser $(0.5 \% \mathrm{w} / \mathrm{w}$ on polymer $)$.

Films of polyethylene were cast from solution as follows. The polymer was blended with decalin at $160^{\circ} \mathrm{C}$ for 45 min. The resulting, highly viscous, solution was compression-moulded at $160^{\circ} \mathrm{C}$ and subsequently quenched to room temperature. In the case of the very dilute solutions, 1 and $2 \% \mathrm{v} / \mathrm{v}$, the films were cast directly from solution onto a cooled glass-plate. The gel-films, obtained on quenching, were dried at ambient temperature and the last traces of decalin were extracted with hexane. The dried films were slightly compressed at room temperature to obtain a flat surface and to remove voids. Dumb-bell shaped specimens with a length of $20 \mathrm{~mm}$ and a width of $2 \mathrm{~mm}$ were cut from the films (thickness about $0.15 \mathrm{~mm}$ ).

The hot-drawing behaviour of these samples was studied using an Instron tensile tester, equipped with a hot-air oven. 
The drawing experiments were performed at $120^{\circ} \mathrm{C}$ using a cross-head speed of $100 \mathrm{~mm} / \mathrm{min}$. The draw ratio was determined by measuring the displacement of ink marks, placed $1 \mathrm{~mm}$ apart onto the specimen prior to drawing. Room temperature tensile properties were measured on samples with an initial length of $50 \mathrm{~mm}$. The testing speed was $5 \mathrm{~mm} / \mathrm{min}$

\section{RESULTS AND DISCUSSION}

Table 1 shows the results of drawing high molecular weight polyethylene, Hostalen Gur, cast from solution via gelation/ crystallisation. Here the initial volume fraction of polymer is represented by $\phi$. The maximum attainable draw ratio $\left(\lambda_{\max }\right)$ refers to drawing at $120^{\circ} \mathrm{C}$. Young's modulus (E) and the tensile strength $(\sigma)$ were measured at room temperature on samples which were drawn at $120^{\circ} \mathrm{C}$ close to $\lambda_{\max }$.

Table 1. Relation between initial polyethylene volume fraction $(\phi)$ and maximum draw ratio $\left(\lambda_{\max }\right)$ at $120^{\circ} \mathrm{C}$ of solution-cast films, and corresponding room temperature Young's modulus (E) and tensile strength $(\sigma)$

\begin{tabular}{llll}
\hline$\phi$ & $\begin{array}{l}\lambda_{\max } \text { at } \\
120^{\circ} \mathrm{C}\end{array}$ & $E, G P_{a}$ & $\sigma, G P_{a}$ \\
\hline 1.00 & 6 & 10 & 0.5 \\
0.14 & 17 & 41 & 1.5 \\
0.10 & 24 & 68 & 2.3 \\
0.08 & 23 & 62 & 2.3 \\
0.02 & 46 & 110 & 3.0 \\
0.01 & 72 & 120 & 3.2 \\
\hline
\end{tabular}

Of course, $\lambda_{\max }$ depends on many experimental variables, like drawing temperature, rate, etc. Table 1 nevertheless shows the strong increase in drawability with decreasing $\phi$ under standard experimental conditions. It is now well established that both the tensile strength and Young's modulus increase with increasing draw ratio, at least in the temperature range below the end-melting temperature. ${ }^{7,14}$ Consequently by increasing $\lambda_{\max }$ through casting from semidilute solutions via gelation/crystallisation a major improvement in mechanical properties can be obtained in comparison with drawing of melt-crystallised samples. Thus, a low initial polymer concentration is advantageous to promote the drawability. Of course, it is not possible to reduce the initial polymer volume fraction in solution to very low values. In such dilute solutions loose single crystals precipitate on cooling and no coherent gels are generated. For the present polymer sample the practical lower limit is about $0.1 \%$ by volume. On quenching this and more dilute solutions less coherent gels are obtained exhibiting unstable draw, ${ }^{15}$ or premature fracture.

The drastically improved effective drawability of solutioncast high molecular weight polyethylene can be explained, at least in a qualitative way, as follows. During dissolution, the highly entangled polymer molecules expand and the number of entanglements per macromolecule decreases approximately proportionally with the volume fraction of the polymer, provided that the coil-overlap concentration is exceeded. ${ }^{16}$ Upon quenching such semi-dilute solutions gelation-crystallisation takes place and a coherent gel is obtained, in which the disentangled state of the macro. molecules is at least partially retained. ${ }^{17}$ Once this gelstructure with a reduced number of trapped entanglements is laid down, removal of solvent but moderately affects the beneficial change in drawability. ${ }^{13,14}$ Hence, in our view, the number of entanglements trapped during solidification is the dominant feature governing draw at elevated temperatures. This explanation is quite in conflict with recently published results, where the increased drawability of high molecular weight polyethylene spun from solution was related to residual porosity in the extracted gel-fibres. ${ }^{18}$ We found that compression moulding of extracted gels of polyethylene did not reduce their drawability, although this treatment caused an increase of the apparent, macroscopic, density from $500-700 \mathrm{~kg} / \mathrm{m}^{3}$ to about $940-960$ $\mathrm{kg} / \mathrm{m}^{3}$, which was in accordance with the density of the pure polyethylene. In fact, this result is rather obvious, since drawing involves rearrangement of macromolecules and macroscopic porosity originating from removal of solvent located in between the crystallites of the gel, does not affect processes on molecular scale. If it did, polyethylene foam would be the ideal precursor for high-strength polyethylene fibres.

At this point we want to address the structure of the polyethylene gels obtained by quenching semi-dilute and more concentrated solutions. In our opinion such gels of linear polyethylene can be considered as interconnected, highly solvated lamellar crystallites. This is illustrated in Figure 1 , where a scanning electron micrograph is presented of a polyethylene gel obtained by quenching a $2 \%$ solution of Hostalen GUR in decalin (removal of the solvent was performed by extraction with hexane and subsequent drying) This micrograph clearly shows the lamellar nature of the crystallites in the gel, and the connectivity of the individual crystals (see also ref. 19).

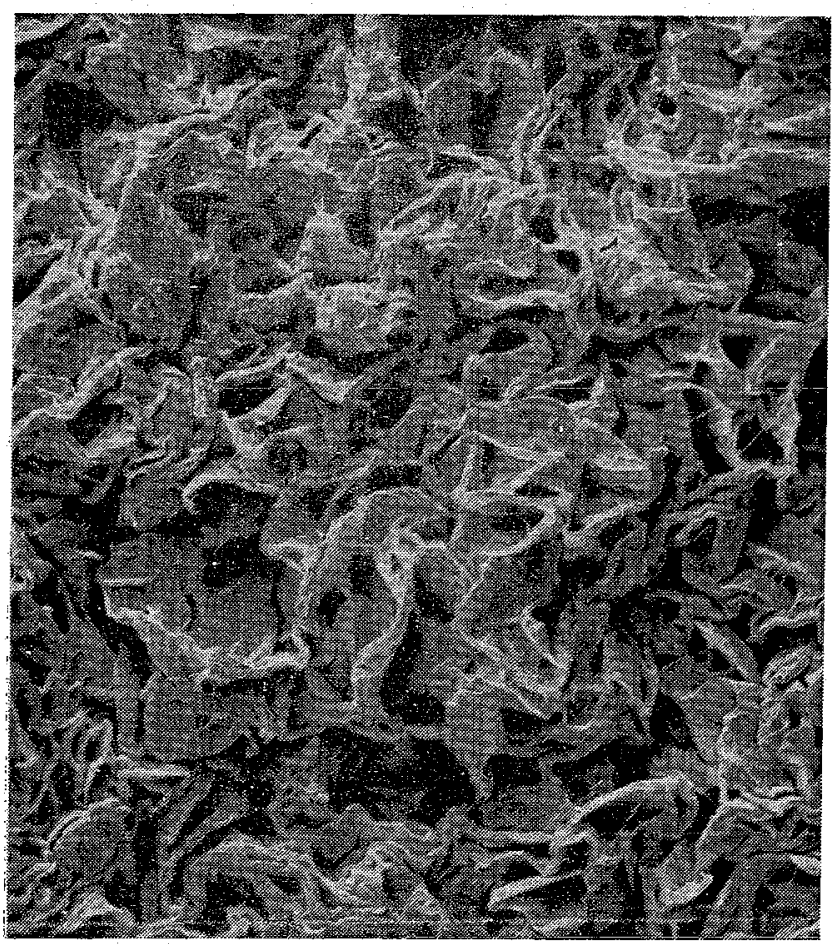

Fig.1 Scanning electron micrograph of polyethylene structure obtained by gelation-crystallisation of a $2 \% \mathrm{v} / \mathrm{v}$ solution in decalin, and subsequent extraction of the solvent. Magnification 1000x.

We hasten to add that other modes of gel-formation exist and, depending on preparation conditions such as flow history, polyethylene gels may contain both lamellar type crystals and shish-kebab structures. ${ }^{20}$ The latter morphology is, in fact, necessary to obtain coherent gels from dilute solutions where chain overlap hardly exists. However, in our preparation we try to avoid extensive 
shish-kebab formation, which generally has a negative influence on the drawability. Figure 2 displays an electron micrograph of an extracted and dried gel of the identical high molecular weight polyethylene sample, but now the $2 \%$ solution was stirred vigorously at $160^{\circ} \mathrm{C}$, prior to quenching. The abundance of shish-kebab structures, clearly shown in this picture, is obviously related to the mechanical agitation of the solution. When the stiried solution was kept at $160^{\circ} \mathrm{C}$ for about 45 minutes, the formation of shish-kebabs could be avoided to a large extent, due to relaxation of the macromolecules.

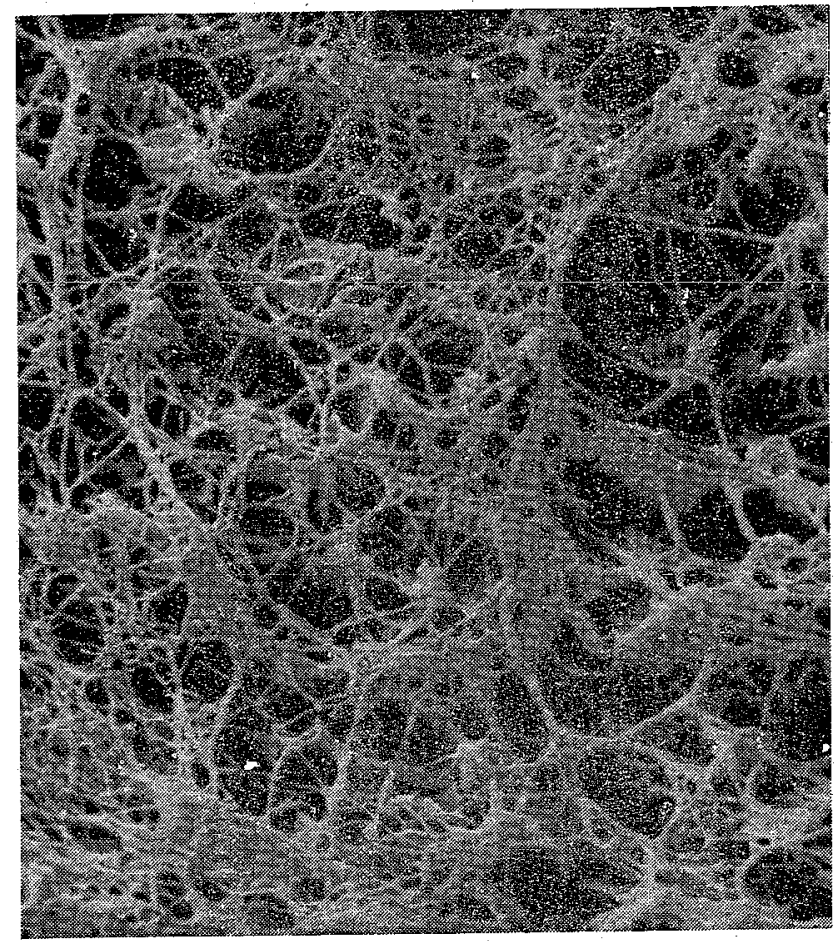

Fig.2 Scanning electron micrograph of polyethylene structure produced as in Fig.1, but vigorous stirring was applied at $160^{\circ} \mathrm{C}$, prior to quenching. Magnification 2500x.

The discussion presented on the enhancement of the drawability of high molecular weight polyethylene through casting from semi-dilute solution was entirely based on a reduction of the number of trapped entanglements in the polymer solid. The contribution of crystallites on the drawing behaviour of polyethylene was completely ignored. This simple picture of drawing might cause confusion, at first sight. It should be noted, however, that ultra-drawing of polyethylene can be performed successfully primarily in a temperature range above the $\alpha$-relaxation temperature, which is about $60-70^{\circ} \mathrm{C}$, and below the end-melting temperature. In this range polyethylene crystals are known to yield and deform readily 21 and, consequently, do not act as rigid bodies during draw, but rather give rise to a high viscosity and prevent extensive chain slippage and recoiling of extended macromolecules. The trapped entanglements may, on the other hand, be considered as semi-permanent cross-links on the time scale of the drawing experiment. This concept is not in conflict with results obtained in drawing melt-crystallised polyethylene. It has been shown that slow cooling from the melt promotes the drawability in comparison with quenched samples. ${ }^{10}$ On slow cooling one might expect the number of entanglements per macromolecule to decrease due to reeling-in of the chains onto the crystal growth surfaces, in contrast to quenching where the highly entangled liquid state is retained to a large extent. ${ }^{17}$ In the solidification of very high molecular weight polyethylene reeling-in is largely impeded and crystallisation conditions only slightly affect the drawability of these materials. ${ }^{10}$

In summary, gelation-crystallisation is advantageous to promote effective drawing of high molecular weight polyethylene and thus to exploit the full potential of this particular polymer with respect to strength and stiffness.

\section{ACKNOWLEDGEMENT}

The authors wish to thank S. M. G. Nadorp for taking the scanning electron micrographs, and J. P. L. Pijpers for experimental assistance.

\section{References}

1 Ciferri, A. \& Ward, I. M., Ultra-High Modulus Polymers, 1979, London: Applied Science Publisher.

2 Schaefgen, J. R., Bair, T. I., Ballou, J. W., Kwolek, S. L., Morgan, P. W., Panar, M. \& Zimmerman, J., ibid, p173.

3 Wooten, W. C., McFarlane, F. E., Gray, T. F. \& Jackson, W. J., ibid, p227.

4 Kausch, H. H., Polymer Fracture, 1978, Heidelberg: SpringerVerlag.

5 Boudreaux, D. S., J. Polym. Sci.Polymer Physics Ed., 1973, 11,1285

6 Southern, J. H. \& Porter, R. S., J. Appl. Polym. Sci., 1970, 14, 2305.

7 Capaccio, G., Crompton, T. A. \& Ward, I. M., Polymer, 1976, 17,664 .

8 Flory, P. J., J. Am. chem. Soc., 1945, 67, 2048.

9 Smith,P. \& Lemstra, P. J., J. Polym. Sci., Polym. Phys. Ed., in the press.

10 Capaccio, G., Gibson, A. G. \& Ward, I. M., Reference 1, p7, Fig.4.

11 Smith, P. \& Lemstra, P. J., J. Mater. Sci., 1980, 15, 505.

12 Idem, Colloid and Polym. Sci., 1980, 258, 891.

13 Idem, Makromol. Chem., 1979, 180, 2983.

14 Idem, Polymer, 1980, 21, 1341.

15 Smith, P., Lemstra, P. J.\& Booij, H. C., J. Polym. SciPolymer Physics Ed., in the press.

Graessly, W. W., Adv. Polym. Sci., 1974, 16.

Peterlin, A., Macromolecules, 1980, 13/4, 777.

Kalb, B. \& Pennings, A. J., Polymer, 1980, 21, 3.

Keith, H. D., Padden, F. J. \& Vadimsky, R. G., J. Appl.

Phys., 1971, 42, 4585.

20 Barham, P. J., Hill, M. J. \& Keller, A., Colloid and Polym. Sci., 258, 899.

21 Sauer, J. A., Richardson, G. C. \& Morrow, D. R., J. Macromol. Sci.Revs. Macromol. Chem., 1973, C9, 149. 